\title{
Dynamic Transmission Electron Microscope Investigations of Dynamic Processes in Materials
}

\author{
M. K. Santala, ${ }^{1}$ S. Meister,${ }^{2}$ B. W. Reed,${ }^{1}$ T. LaGrange, ${ }^{1}$ J. E. Evans, ${ }^{1,3}$ G. H. Campbell, ${ }^{1}$ \\ and N. D. Browning ${ }^{1,3,4}$
}

1. Condensed Matter \& Materials Division, Physical and Life Sciences Directorate, Lawrence Livermore National Laboratory, 7000 East Avenue, Livermore, CA, 94551

2. Materials Science and Engineering, Stanford University, 476 Lomita Mall, Stanford, CA, 94305

3. Department of Chemical Engineering and Materials Science, University of California, Davis, 1 Shields Ave., Davis, CA 95616

4. Department of Molecular and Cellular Biology, University of California, Davis, 1 Shields Ave., Davis, CA 95616

Dynamic transmission electron microscope (DTEM) has proved to be a powerful tool in the study of dynamic events, such as phase transformations, in metals and semiconductors [1], and is now showing its usefulness in the study of a broad range of materials systems, as diverse as chalcogenide-based phasechange materials and biological materials. Our most recent results in nanosecond-scale time-resolved imaging and diffraction on materials processes will be described.

For example, $\mathrm{Ge}_{2} \mathrm{Sb}_{2} \mathrm{Te}_{5}$ is a chalcogenide-alloy phase-change material that is technologically significant because of its wide use in optical recording media and its promising potential for use in non-volatile electronic memory [2]. For either application, rapid switching between the amorphous and crystalline phases is necessary for rapid recording of data, and understanding the kinetics of phase transition at very short time scales is of both scientific and technological interest. The time for laser-induced crystallization ( $\sim 100 \mathrm{~ns})$ and the melt/quench process ( 10ns) [3] are on the scale ideally probed with the DTEM.

Phase transformations in continuous and micro-patterned thin films of $\mathrm{Ge}_{2} \mathrm{Sb}_{2} \mathrm{Te}_{5}$ were induced with a $15 \mathrm{~ns}$ laser pulses in a DTEM. The influence of specimen geometry on laser absorption was studied in situ with micro-patterned films. The amorphous-crystalline phase transformations, grain growth (FIG 2), and melting-solidification transitions (FIG 3) were observed and the kinetics of these processes were revealed by time-resolved TEM imaging and electron diffraction on nanosecond time scales [4].

\section{References}

[1] T. LaGrange, G. H. Campbell, B. W. Reed, M. Taheri, J. Bradley Pesavento, J. S. Kim, N. D. Browning, Ultramicroscopy 108 (2008) 1441-9.

[2] M. Wuttig and C. Steimer, Appl. Phys. A-Mater. 87 (2007) 411-7.

[3] V. Wiedenhof, I. Friedrich, S.Ziegler, and M. Wuttig, J. Appl. Phys. 89 (2001) 3168-76.

[4] This work performed under the auspices of the U.S. Department of Energy, Office of Basic Energy Sciences, Division of Materials Sciences and Engineering by Lawrence Livermore National Laboratory under Contract DE-AC52-07NA27344. 


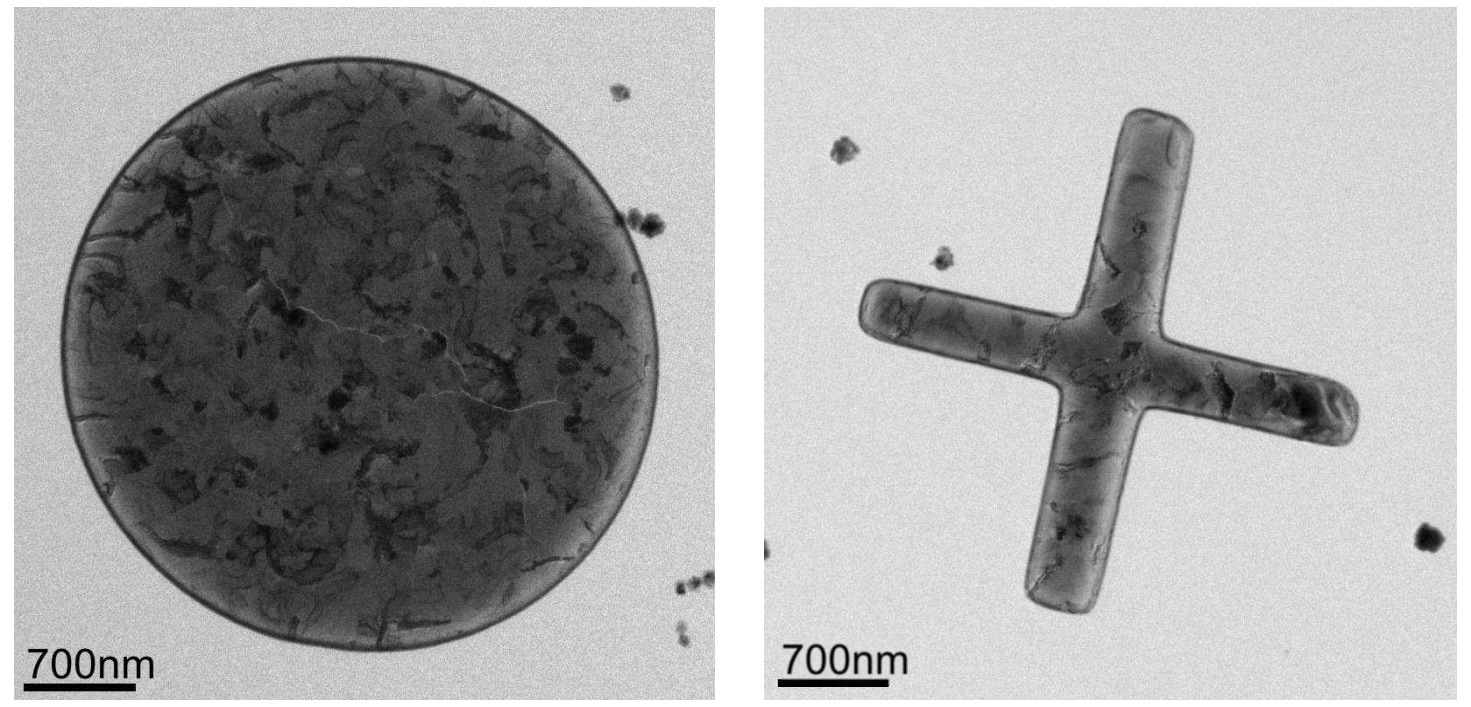

FIG 1 Bright field TEM images of micropatterned $\mathrm{Ge}_{2} \mathrm{Sb}_{2} \mathrm{Te}_{5}$ thin films, as deposited.
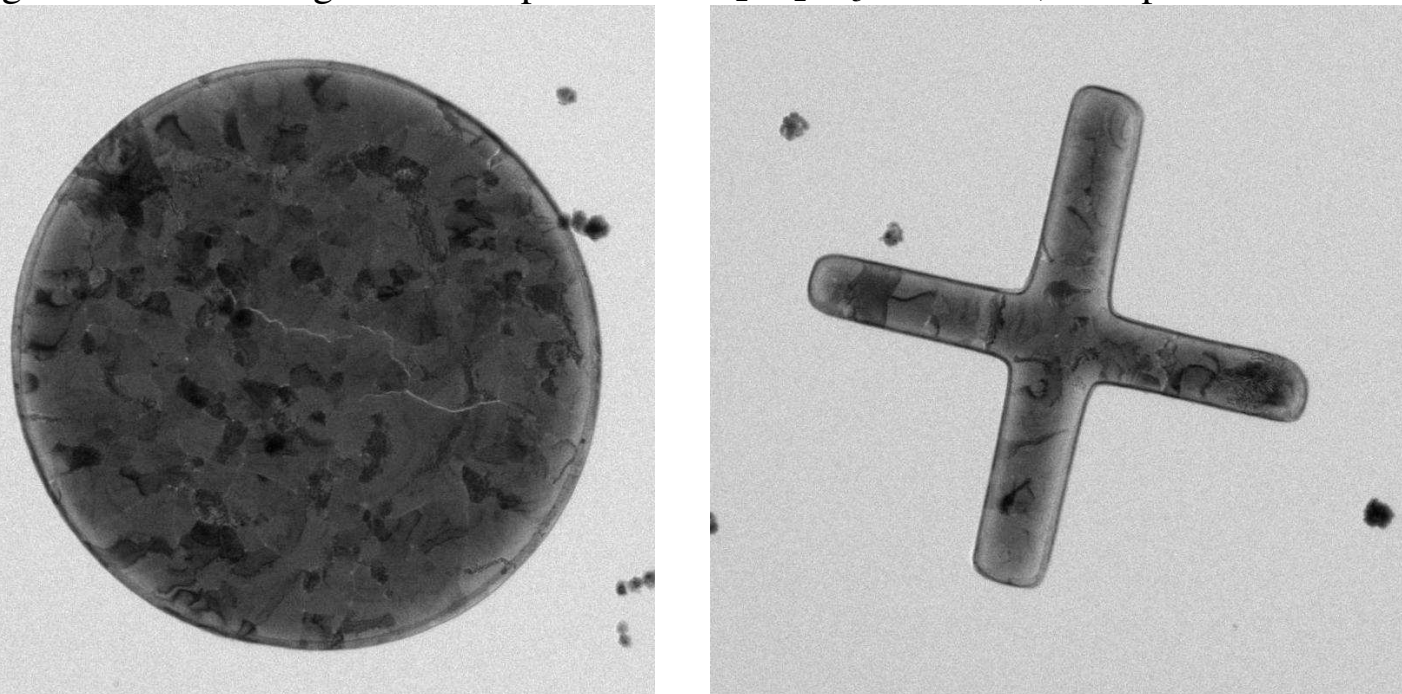

FIG 2 As in FIG 1, after exposure to a $15 \mathrm{~ns}, 2 \mu \mathrm{J}$ laser pulse $\left(1 / \mathrm{e}^{2}\right.$ diameter of $\left.\sim 300 \mu \mathrm{m}, \lambda=532 \mathrm{~nm}\right)$.
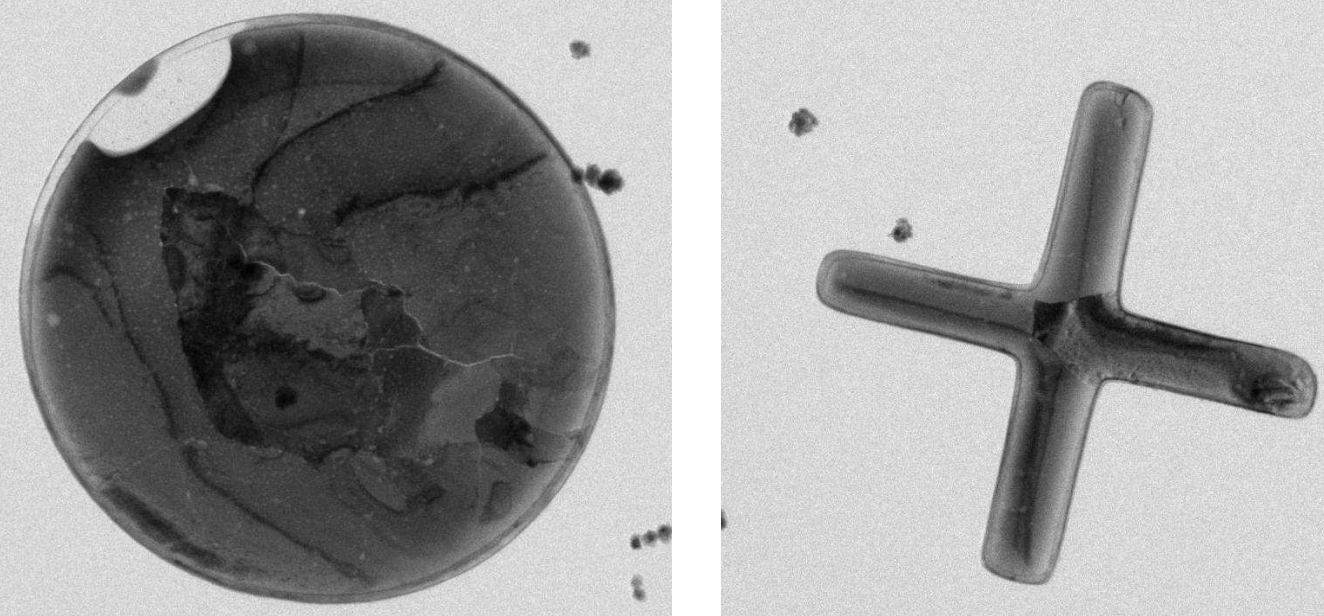

FIG 3 As in FIG 2, after melting and re-solidification caused by exposure to a $15 \mathrm{~ns}, 3 \mu \mathrm{J}$ laser pulse. 